Proceedings of the Institution of
Civil Engineers
Engineering Sustainability 156
September 2003 Issue ES3
Pages I39-145
Paper 13415
Received 23/06/2003
Accepted I $3 / 08 / 2003$
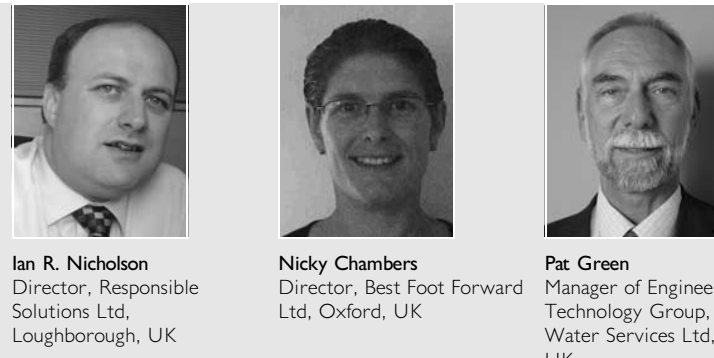

Nicky Chambers

Director, Best Foot Forward Manager of Engineering,

Ltd, Oxford, UK Technology Group, Anglian

Water Services Ltd, Oxford

UK

\title{
Ecological footprint analysis as a project assessment tool
}

\section{R. Nicholson, N. Chambers and P. Green}

With the UK Government now committed to promoting eco-efficiency through the Sustainable Consumption and Production programme, the role of eco-efficiency metrics and associated sustainability metrics is becoming ever more important. Business has a key role to play in actually delivering sustainability, and business-friendly metrics are vital in informing decision-making as well as monitoring progress. This paper describes how ecological footprinting can measure the environmental impacts of projects and services and, more challengingly, relate those impacts to global environmental sustainability. The research described in this paper shows how ecological footprinting has been used at the project planning stage, to appraise possible construction options in the context of sustainable production and consumption.

\section{BUSINESS INDICATORS OF ECOLOGICAL SUSTAINABILITY}

Business indicators of sustainability serve two key purposes. First, they provide an indication of internal eco-efficiency. Is the business going in the right direction and getting more from less? Is society getting more value from fewer resources? To determine this, there needs to be linkage between how much we are consuming and the value created. Carefully constructed eco-efficiency indicators, where the value created is expressed in terms of service value such as product numbers or services delivered, can tell us part of the story. Such analyses facilitate useful benchmarking between different processes, projects or indeed companies. These benefits can be achieved using many of the existing measures of eco-efficiency such as energy consumed per unit of service. Ecological footprinting can also be used as an eco-efficiency indicator. For example, early work at Anglian Water Services showed that the average ecological footprint of Anglian's water services in 1999 was 0.22 global hectares per megalitre (gha/Ml). From this average the relative environmental performance of different types of treatment plant can be identified, and if other company data were available it would be possible to compare the performance of different companies.

In addition, business sustainability indicators need to be linked to the finite availability of resources - or carrying capacity. They need to inform us about how the production and consumption of goods and services makes use of natural capital: how much carrying capacity is being appropriated for the production of resources and assimilation of wastes.
According to the World Business Council for Sustainable Development, eco-efficiency is 'progressively reducing ecological impacts and resource intensity throughout the life cycle, to a level at least in line with the earth's estimated carrying capacity. ${ }^{1}$ Ecological footprinting, which can be used both as an eco-efficiency indicator and as a global sustainability indicator, provides the vital link between the local and the global, and between production and consumption. For example, the research work at Anglian Water Services showed that the 1999 ecological footprint of its water services was 0.01 gha per customer. To assess the scale of this impact in terms of sustainability, this figure can be compared with the average per capita earthshare: that is, the amount of land available to each person on the planet, if it were divided equally. In 1999 this average earthshare was 1.87 gha, so it can be deduced that about $0.5 \%$ of each customer's earthshare was 'spent' on water services.

\section{WHAT IS ECOLOGICAL FOOTPRINTING?}

The ecological footprint is a means of measuring and communicating human-induced environmental impacts upon the planet. Although it was initially used to measure the impact of countries, Best Foot Forward has developed a 'component' methodology to be applicable to a wide range of users. ${ }^{2}$ The components used are
(a) energy
(b) materials and waste
(c) transport
(d) food
(e) water
(f) built land.

This 'bottom-up' approach allows the impacts of these component activities to be related to the types of land required to support them. The land categories used are

(a) bioproductive land

(b) bioproductive sea

(c) energy land (forested land required for the absorption of carbon emissions)

(d) built land (such as buildings and roads).

A fifth land type, biodiversity land, refers to the area of land that would need to be set aside to preserve biodiversity. 


\begin{tabular}{lcccc}
\hline Component & Inputs & $\mathrm{CO}_{2}$ emissions & Built-upon land & Footprint \\
\hline Energy $^{4}$ & $74 \mathrm{G}$ ) & $9620 \mathrm{~kg}$ & & 3.28 gha $(d)$ \\
Degraded land $^{5}$ & 0.000030 gha $(a)$ & & & \\
Waste factor $^{6}$ & $1.6(\mathrm{~b})$ & & $a \times b$ & $c+d$ \\
Calculation & & & 0.000049 gha $(c)$ & 3.28 gha \\
Footprint & & & \\
\hline
\end{tabular}

* The waste factor accounts for the overburden produced in order to obtain the iron ore.

Table I. An example analysis for the footprint of concrete reinforcement (rebar) (c) Presenting construction impacts alongside operational impacts shows which stage is the most significant, and the relative scale of the impact of the different phases.

(d) Normalising the ecological footprint per customer enables comparison of the ecological footprint of the service pro-

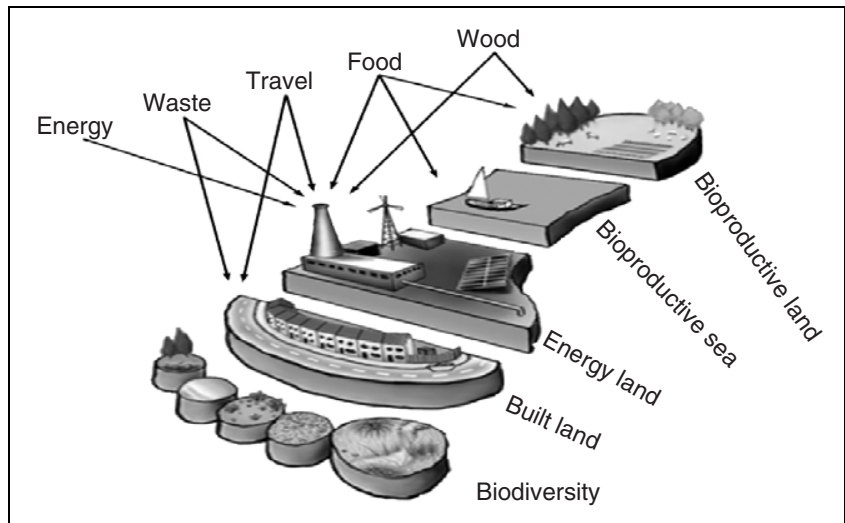

Fig. I. Each activity will appropriate different land types

By creating an ecological footprint for each of the individual energy and material 'flows' within a process or service, a total ecological footprint can be derived by adding together all the individual components.

The ecological footprint presents its results in hectares of "biologically productive space with world average productivity'. ${ }^{3}$ These hectares are termed global hectares (gha) by Wackernagel et al. (quoted in Reference 3). Because biological productivity varies all over the world, global hectares allow fair comparison between locations, as well as with the planet's biologically productive resources.

Table 1 shows an example analysis for the footprint of 1 tonne of rebar (alloy steel).

Where data are available, this approach can also be applied to construction projects. Analyses can be carried out at the planning and design stage to provide a powerful project appraisal tool to assist in decision-making. The analysis can take into account impacts associated with the building of the facility as well as its operation. Depending on the required use of the indicator, the results can be expressed in a variety of ways.

(a) Presenting the ecological footprint by component can highlight areas of high impact, indicating areas worthy of improvement in performance.

(b) Annualising construction impacts over the asset life of the facility and adding that to the annual operational impacts can provide a benchmark measure of the impact of the service provided. This can be used to compare efficiencies of different processes or facilities. vided with the per capita 'average earth shares' to show much of that earthshare is consumed by provision of that service.

The ecological footprinting is a novel evaluation methodology, and is not without its flaws. ${ }^{*}$ However, many of these flaws are rooted in problems of data availability and data sensitivity common to other evaluation methodologies. The most significant is identifying comprehensive life-cycle data on materials, products or activities. As with most other evaluation methods, steps are taken to minimise uncertainties, such as the use of official or validated data sets. Where this is not possible, the preference is to use the more conservative estimates of impact. In addition, where it is desirable for the results to be comparable with the established studies, data that are compatible with those studies are necessarily used.

Another limitation of ecological footprinting is that it does not currently integrate the effects of toxic pollution, and it is recommended that these are assessed separately. Although some work has been done on integration of these effects it is not included, partly because it is significantly less robust than the standard approach and partly because inclusion would make results incompatible with the National Footprint accounts published by WWF. ${ }^{3}$

This use of ecological footprinting for project appraisals is new and will undoubtedly need to develop over time, as this paper demonstrates. As with other evaluation methodologies, ecological footprinting would benefit significantly from better lifecycle data on construction materials.

The work at Anglian Water Services shows the potential of the methodology in assisting with decision-making for capital projects. The remainder of this paper will describe how Anglian Water Services carries out project appraisal, why ecological footprinting was selected, and the detail of how it is being applied.

\section{PROJECT APPRAISAL IN ANGLIAN WATER}

Traditionally, options for the construction of capital solutions have been assessed using a simple net present value (NPV) analysis. This method assesses, over the life of the asset, the initial capital cost, replacement capital cost and operating cost, and reduces these to a single NPV using a suitable discount factor, often around $8 \%$. The NPV for each option considered is

* Further criticisms and responses can be found at http://www.bestfootforward.com 
determined, and the lowest is usually selected. This process is further refined by a risk analysis of each option, and the combination of NPV and risk determines which option is chosen. This analysis is conducted through a process of stakeholder involvement, which ensures that the full scope of the problem and its solution are understood before a final decision is made. This is known in Anglian Water as the value management process, and takes place at predetermined stages of the project's life, culminating in a post-project feedback session to determine whether the objectives of the project were met.

Anglian Water has been committed to the concept of sustainable development since the mid-1990s. This commitment extends into the delivery of the capital investment programme for the East Anglian region. Although investment decisions have been made using the value management methodology described above for a number of years, it became apparent that this process lacked an objective assessment of environmental impact for the different project options. A journey therefore began in the early part of 2000 to find a tool that could assist in this process-a journey because there are certainly no definitive conclusions, and a lot of things have been learnt along the way, as this paper will show. As a result, the value management process can now be further informed by the introduction of ecological footprinting. Each option can now be analysed for a simple quantitative measurement that will summarise the effect of the project's construction and subsequent operation on the total consumption of natural resources. Thus the most appropriate solution can be chosen, with a clear, detailed record of how the decision was reached.

\section{WHY ECOLOGICAL FOOTPRINTING?}

A number of different tools were looked at in the early stages; these included the Movement for Innovation (M4I) Sustainability Toolkit, ${ }^{7}$ Sustainability Profiles from Forum for the Future, ${ }^{8}$ and ecological footprinting as developed by Best Foot Forward.

Ecological footprinting was selected for a number of reasons. It overcomes the problem of some of the other tools reviewed because of the objective nature of the measurement, where conversion factors are based on biological principles rather than on weighted values. The fact that a single number is derived at the end of the process makes it simple in two ways: first, it can sit alongside the traditional evaluation of NPV and risk; second, with a single number answer it is much easier to identify the better environmental option. With more traditional life-cycle analysis tools, which can give around 13 different emissions values, it can be difficult to identify the best option clearly without some form of subjective prioritisation of the different emission types. A single-number answer also makes communication of the environmental impact much easier, particularly as it is expressed in land area, a unit that most people can comprehend. It also builds on work done in 1998 to develop Anglian Water Services' corporate ecological footprint. This work was published in the ACCA report Ecological Footprint Analysis: Towards a Sustainability Indicator for Business. ${ }^{9}$

Probably more important from a communications viewpoint is the fact that ecological footprinting links impact to the carrying capacity of the planet, and so it is possible to normalise data to show how the project impacts on the capacity of the earth. This is demonstrated later in this paper.

One of the main criteria for the development of a project assessment tool was the need for project teams to be able to develop the footprint quickly and easily with the minimum of data input. It was therefore decided that a spreadsheet-based calculator should be developed to assist the deployment of environmental assessment.

The first stage of this development was to analyse as fully as possible a completed or nearly completed project to identify significant environmental impacts and hence the key data points that would be required for the calculator. To achieve this, Ingoldmells wastewater treatment works on the Lincolnshire coast was selected. This site was chosen because it was just being completed, so records were still available; it was completed under an open book contract, so data from the contractor were easily accessible; and it was a very typical wastewater scheme, including primary, secondary and sludge treatment stages.

\section{THE ECOLOGICAL FOOTPRINT OF INGOLDMELLS WASTEWATER TREATMENT WORKS}

Ingoldmells wastewater treatment works, located near Skegness, treats the wastewater from a population of about 30000 in winter to a maximum of 170000 in summer. The works was developed to meet the provisions of the Urban Wastewater Treatment Directive, and consists of screening, de-gritting and initial settlement in three tanks followed by biological treatment by the activated sludge process, in which pollutants are oxidised by micro-organisms suspended in a large aerated tank. This is followed by further settlement to produce a clear effluent. Sludge from the process is de-watered in centrifuges to form a cake. Construction started in 1999 and was complete by 2001.

\section{I. Data collection}

Before data are collected it is vital to define the boundaries of the project and what the analysis is going to measure. This is particularly important where comparative analyses of, for example, processes are to be made, to ensure that like is compared with like. For this project, data were collected for the energy and materials consumed and waste produced in the construction process and for the operation of the project, taking care not to double-count impacts between components. Ecological footprint conversion factors based on life-cycle impacts are applied to consumption data, again taking care that impacts throughout the life cycle are included but not double-counted. For example, impacts associated with fuel used for transporting materials may already be included in embodied energy estimates of materials as well as in additional freight transport data.

To focus data collection efforts, it is helpful to have a good understanding of the significant resource consumption categories of the projects and where they arise in the construction and operation processes. For Ingoldmells these significant impacts had not already been identified, and therefore data collection was a very comprehensive process. All 'materials received' sheets, plant returns and subcontract documents were 
analysed to arrive at a data set of the most significant consumption categories.

This proved to be straightforward, but time-consuming. The only difficult area was that of quantifying the weights of subcontract items, such as scraper bridges and conveyors. These tend to be priced on a lump sum basis with no detailed breakdown of material usage. In some cases even the subcontractors themselves did not know the weight of the items they were supplying. To provide the most accurate data input possible some of these items were measured on site for lengths, section sizes etc. and weights were then calculated.

This level of detail was only necessary in this instance to gather a comprehensive data set from which significant or priority resource impacts could be identified. This ensured that the resultant assessment calculator would contain the most appropriate data points. Subsequent analyses using the calculator, which focused on the key data points, would have a much simpler and quicker data collection process.

\subsection{The results}

The results, shown in Fig. 2, were broken down to show the operational and construction footprints for the project. Note that, because most energy in the construction phase arises from diesel consumption in plant construction, energy comes under the heading of transport.

Figure 2 shows an interesting point that had to be overcome. Whereas the operational footprint can easily be calculated on an annual basis, calculation of the construction impacts on an annual basis requires the asset life to be accounted for. Initially the construction footprint was annualised over the anticipated asset life of 40 years. However, this gave a skewed picture of the footprint because different elements of the project have very different asset lives, and some elements - such as fuel consumption-are consumed only during the actual construction period. It was therefore decided to leave the construction footprint as an overall impact and not annualise it, so that the results were more transparent.

This representation highlights a key issue in identifying activities with significant impacts - the comparison of initial construction impacts with year-on-year operational impacts. Fig. 3 shows this issue. The solid line represents the ecological footprint for each year at Ingoldmells; starting in years 1-3

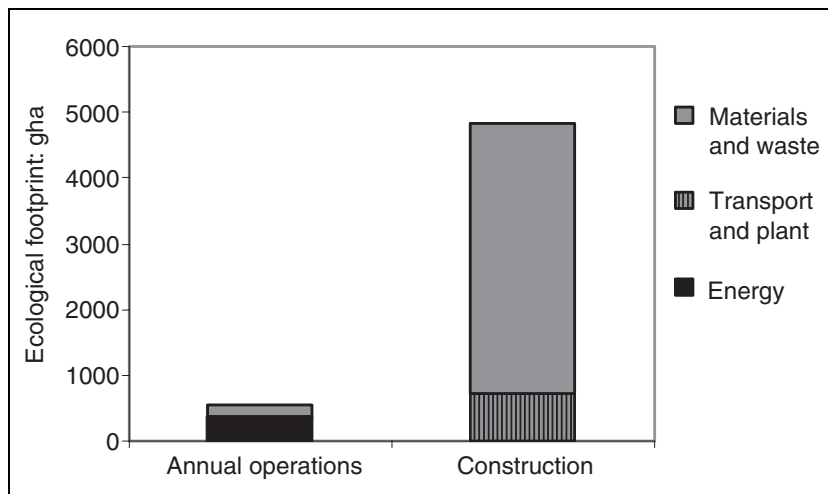

Fig. 2. The annual operational and construction ecological footprint for the whole works

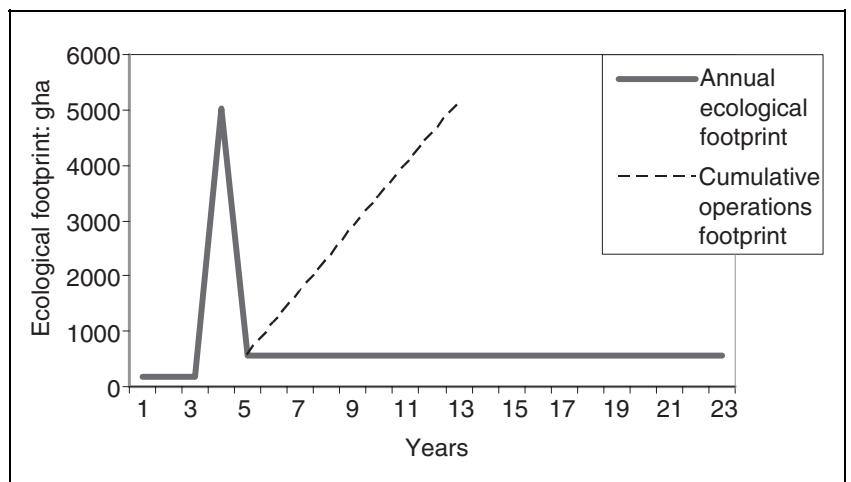

Fig. 3. Timeline showing ecological footprint generated each year

with the operational footprint of the existing works, the large spike in year 4 shows the footprint of the construction work, and year 5 onwards shows the increased operational footprint of the new works. Initial interpretation of this solid line indicates that the construction impact is the most significant element. However, the dotted line shows the cumulative impact of operating the new works. As can be seen in the graph, once the plant has been operating for approximately 10 years the operational impacts become more significant than those in the construction phase. Deciding whether the design should focus on operational issues or construction issues is therefore all down to the asset life - a very interesting debate within the water industry given the frequency of updates to water quality legislation and the subsequent revisiting of sites to carry out further capital investment.

Although this debate is important, it was to some extent a side issue to the primary reason for carrying out the analysis- that of developing a calculator for simple project assessments. To aid this primary objective, the footprint at Ingoldmells was further subdivided to identify the footprint of individual materials and components within both the operation and the construction of the scheme. This identified some interesting findings, as shown in Figs 4 and 5.

Figure 4 shows unsurprisingly that concrete and, in particular, its reinforcement form the two most significant elements of the footprint. However, most concrete structures will be in place for up to 40 years or more, with only minor alterations to them during that time. So when this is taken into account the next

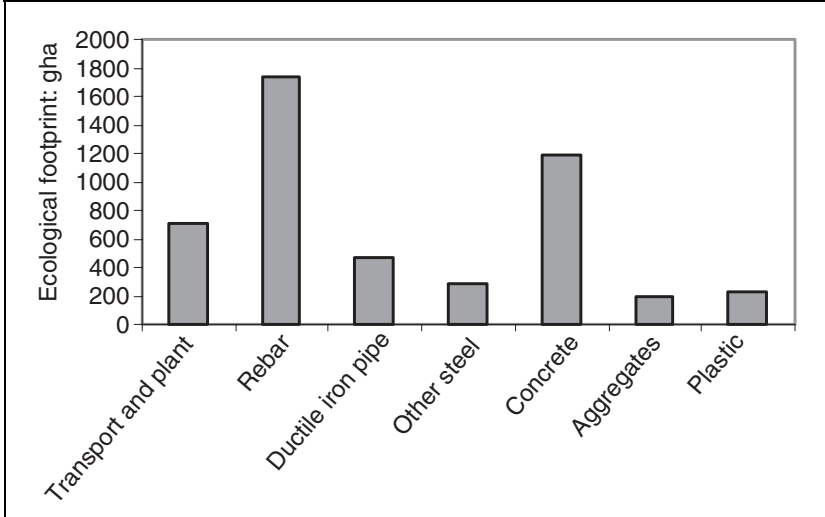

Fig. 4. Significant elements of the construction footprint 


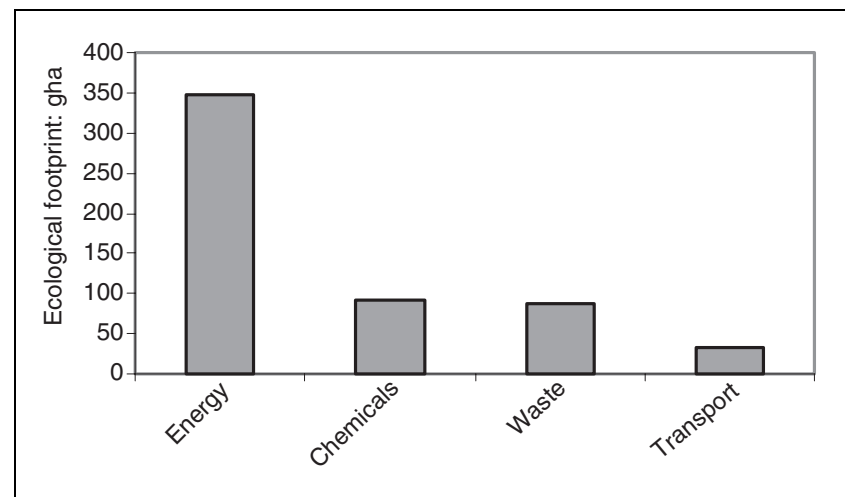

Fig. 5. Significant elements of the annual operational impact

most significant construction impact is that of fuel use: therefore the way we construct is as important as what we construct. Another key finding from this graph is the relatively low impact of the mechanical and electrical (M\&E) equipment. All the steel structures and equipment are included in the "other steel' category, which, as can be seen, is relatively insignificant. Other M\&tE items are covered in plastics, or are so small as not to appear on the graph at all, an example being electric cables. This shows that, although financially the project is split roughly equally between civil and M\&E elements, the environmental impacts break down very differently within the construction footprint.

This is completely reversed when the breakdown of the operational footprint, shown in Fig. 5, is considered. Probably unsurprisingly, energy consumption proves to be the largest component by a significant margin. This is obviously derived from operation of the mechanical and electrical equipment.

Prior to the analysis of Ingoldmells, Anglian Water had used ecological footprinting to analyse the benefits of providing secondary treatment for a project that was still at business case stage. When the breakdown of that project was compared with the breakdown for Ingoldmells shown in Fig. 1, it was found to be almost identical. This shows that a valid analysis can be carried out on outline information with the use of engineering judgementfurther proof that a quick and simple calculator is a viable proposition.

\section{CALCULATOR \\ DEVELOPMENT}

The primary objective for the calculator was that an engineer should be able to produce a footprint within 1-2 hours. This gave a secondary objective of having no more than 25 data entry points. From the detailed breakdown provided at Ingoldmells, we were then able to develop a list of key inputs that the calculator should use. Several items were aggregated to reduce the number of inputs required: so, for instance, concrete reinforcement and concrete were combined, as the quantities of each are tightly tied together. In addition, where unit footprints were very similar they were aggregated to form a single data entry point. For instance, different types of aggregate, steel and plastic were combined into three data points.

In addition to this aggregation various other input options were provided to tie in with corporate objectives. A variety of waste inputs were given to allow differentiation between different material types and whether they were sent to landfill or recycled. Various energy inputs were also provided so that it would be possible to show the effects of generating energy from natural gas, CHP or wind turbines as well as green and brown grid electricity. The full list of data inputs is shown in Table 2.

The output from the calculator was designed to show the relative footprints in each component and also to show the cumulative effect of the footprint over the asset's life.

The output screen is shown in Figs 6 and 7. These show one of the first projects to be assessed using the calculator, a small rural first-time sewerage scheme where the options were for property owners to maintain their own cesspools, or for Anglian Water to provide a small package sewage treatment plant. As described previously, the construction footprint is the total for all the construction works; the operational footprint is an annual footprint; and the total ecological footprint is the product of the asset life entered and the operational footprint plus the construction footprint. The histogram to the left of the pie chart provides a simple guide to indicate whether the operational or construction footprint is more significant over the asset's life.

The results of the analyses were normalised per capita and presented alongside the footprint of two everyday activities (use of a light bulb and driving a car) to illustrate the scale of impact from sewerage services. It also compares the impact of

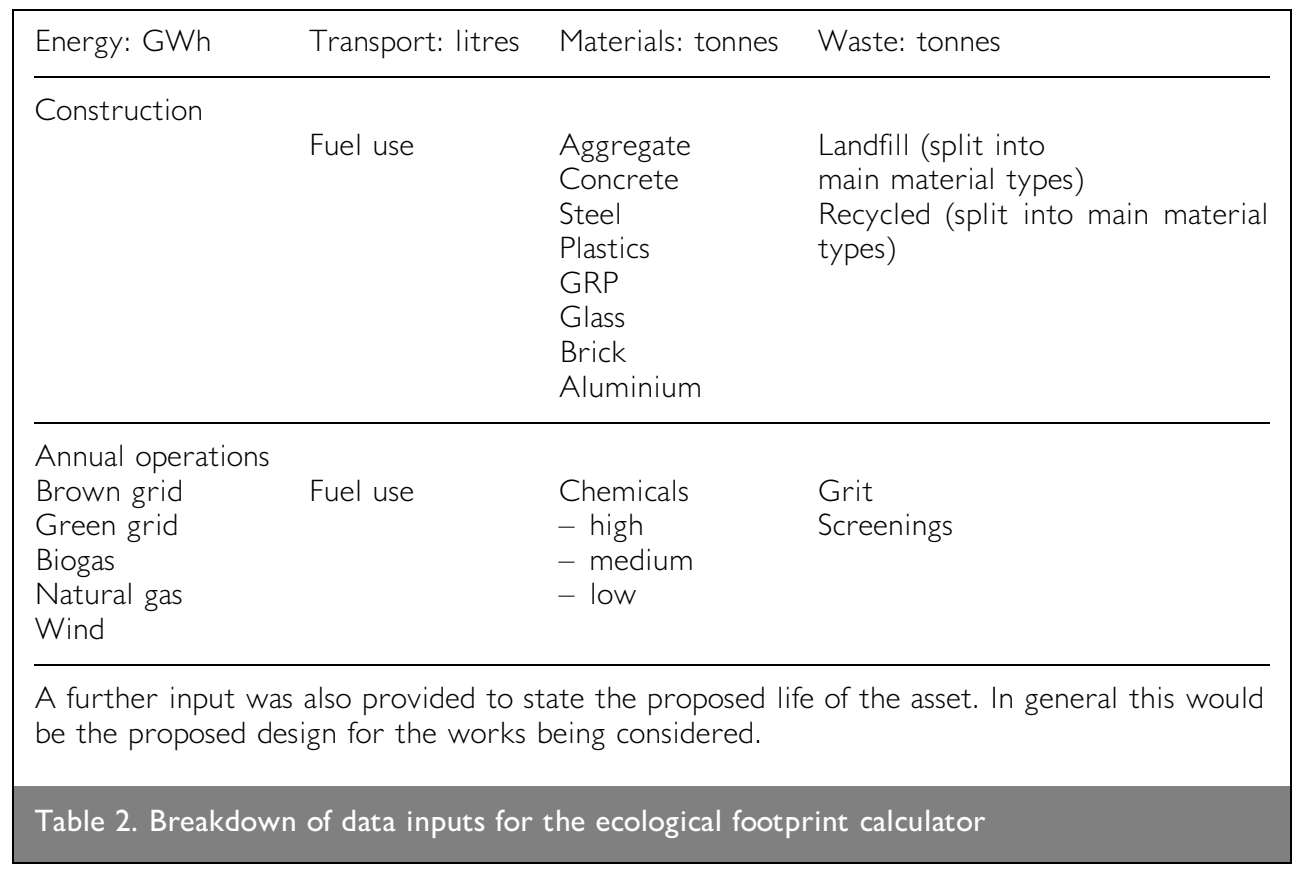




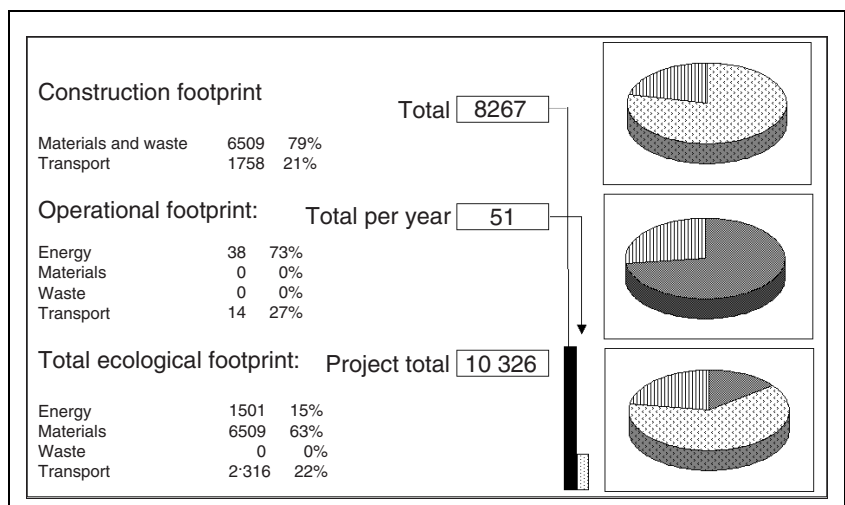

Fig. 6. The ecological footprint of a package sewage

treatment plant. Because of the small scale of the project, all the input quantities were multiplied by 100 to ensure that the footprint was displayed in sufficient detail

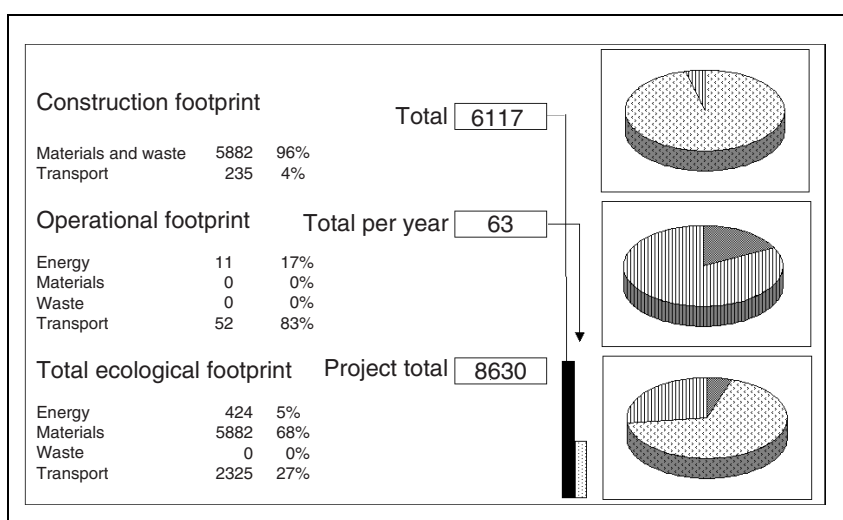

Fig. 7. The ecological footprint of cesspools. Because of the small scale of the project, all the input quantities were multiplied by 100 to ensure that the footprint was displayed in sufficient detail

the scheme with the average footprint of a UK citizen, as published by WWF in their Living Planet Report 2000. ${ }^{3}$ This comparison is shown in Table 3 , and shows the simplicity of the data to enable its communication to non-specialists in a powerful way. In this particular situation it can help a property owner relate the environmental impacts of sewerage services to some understandable everyday equivalents.

\section{NEXT STEPS}

As previously stated, one of the objectives of using ecological footprinting was the ability to use it easily alongside the NPV for the project. Future challenges for this as a methodology will centre on what weighting to give each element of the analysis (NPV, risk, ecological footprint), and depending on location the weighting given to the ecological footprint could differ. More experience is required to determine this.

Even though the calculator is relatively simple to use it does still take somewhat more than the 1-2 hours that we originally set out to achieve. Although this will ease over time as more raw material data are gathered, it is still unlikely to reach the 1-2 hour threshold. This target can be achieved in a number of ways, and first by assessing beforehand the likely benefit of calculating the footprint. The nature of projects within the water industry is such that, on some projects, there are few if

\begin{tabular}{|lcc|} 
& Cesspools & Sewerage \\
\hline Total footprint (40 years) & $86.3 \mathrm{gha}$ & $103.26 \mathrm{gha}$ \\
Footprint per year & $2.158 \mathrm{gha}$ & $2.582 \mathrm{gha}$ \\
$\begin{array}{l}\text { Footprint per capita per } \\
\text { year* }\end{array}$ & $0.0863 \mathrm{gha}$ & $0.10326 \mathrm{gha}$ \\
$\begin{array}{l}\text { Footprint comparisons } \\
\text { No. of } 60 \text { W light bulbs† }\end{array}$ & 1.6 & \\
$\begin{array}{l}\text { No. of km for one person } \\
\text { driving a carł }\end{array}$ & 1876 & 1.92 \\
$\begin{array}{l}\text { Percentage of UK citizens' } \\
\text { footprint\$ }\end{array}$ & 1.37 & 1.64 \\
\hline
\end{tabular}

*Based on a population of 25 .

† This can be compared to the footprint of a $60 \mathrm{~W}$ light bulb lit continuously for I year, which is 0.05375 gha.

$\$$ Another comparison that can be used is the footprint of road transport. The footprint of a car per passenger per $\mathrm{km}$ is 0.000046 gha. $^{10}$

§From the WWF Living Planet report $2000 ;^{3}$ the footprint per UK citizen is 6.3 gha, based on 1996 data.

\section{Table 3. Comparison of sewerage footprints}

any alternatives to how the scheme is delivered. Sometimes the project may have a couple of alternatives, but the only differences may be the type of treatment processes required. This may not affect the core elements of tank sizes and energy consumption, in which case carrying out an ecological footprint analysis may not be a valuable exercise.

A longer-term approach is to build a database of ecological footprint data so that in the future an analysis can be completed by selecting the detailed elements that are required in the project: for example, one final settlement tank $15 \mathrm{~m}$ diameter; and two activated sludge lanes $30 \mathrm{~m}$ long and $5 \mathrm{~m}$ wide. Although this is a good idea in theory, it may be problematic in practice. First, the time required to build the database may be prohibitive, and second the site location will affect the size of footprint because of ground conditions and delivery distances.

During the journey so far many things have been learnt, some of which are outlined in this paper. So the process has definitely been beneficial in raising the awareness of environmental issues within the project teams and in providing a mechanism for communicating environmental impacts in a simple and understandable way to the general public. Whether or not it is a complete success as a project assessment tool is still to be determined. The next step for this is not so much technical development of the tool, as a much wider communication process to engineers and investment decision-makers within Anglian Water to secure buy-in to the use of the tool by demonstrating its benefits.

\section{CONCLUSIONS}

It can be seen that ecological footprinting can help raise awareness of environmental issues, both within the project teams and within the wider public. This is, however, not without its drawbacks with regards to data availability and robustness. However, the work carried out within Anglian Water provides a starting point for these issues to be addressed further. Further development work is also required if Anglian 
Water is to integrate the tool into its investment decisionmaking processes.

The views expressed in this paper are those of the authors and do not necessarily represent the views of Anglian Water, Best Foot Forward or Responsible Solutions

Further information on the use of ecological footprinting can be obtained from the authors: ian@responsible-solutions.co.uk; nicky@bestfootforward.com; pgreen@anglianwater.co.uk

\section{REFERENCES}

1. Available on the internet at: http://www.wbcsd.ch. Last visited 29 July 2003.

2. Chambers N., Simmons C. and Wackernagel M. Sharing Nature's Interest: Ecological Footprints as an Indicator of Sustainability. Earthscan, London, 2000.
3. LoH J. (ed.). Living Planet Report. WWF International, Switzerland, 2000.

4. Matthews R., Robinson R. L., Aвbott S. R. and Fearis N. Modelling of Carbon and Energy Budgets of Wood Fuel Coppice Systems. ETSU B/W5/00337/REP., 1994.

5. Derived from Whitewash in Madagascar, RTZ Mineral Sands Project. Friends of the Earth, 1995.

6. GARDNER G. and SAmpat P. Mind over Matter: Recasting the Role of Materials in our Lives. Worldwatch Paper, December 1998.

7. Available on the internet at: http://www.m4i.org.uk/m4i/ toolkits/sustainability/sustain.asp; last accessed 29 July 2003.

8. Available on the internet at: http://www.forumdirectory. org.uk/aboutus/index2.html; last accessed 29 July 2003.

9. ChAMBERs N. and LeWIS K. Ecological Footprint Analysis: Towards a Sustainability Indicator for Business. The Association of Chartered Certified Accounts, London, 2001.

Please email, fax or post your discussion contributions to the secretary by I March 2004: email: kathleen.hollow@ice.org.uk; fax: +44 (0)20 7799 1325; or post to Kathleen Hollow, Journals Department, Institution of Civil Engineers, I-7 Great George Street, London SWIP 3AA. 